\title{
Nutritional value, bioactive compounds, antimicrobial activity and bioaccessibility studies with wild edible mushrooms
}

Sandrina A. Heleno ${ }^{\mathrm{a}}$, Lillian Barros ${ }^{\mathrm{a}}$, Anabela Martins ${ }^{\mathrm{a}}$, Patricia Morales ${ }^{\mathrm{b}}$, Virginia Fernández-Ruiz $^{\mathrm{b}}$, Jasmina Glamoclija ${ }^{\mathrm{c}}$, Marina Sokovic ${ }^{\mathrm{c}}$, Isabel C.F.R. Ferreira ${ }^{\mathrm{a},{ }^{*}}$

${ }^{a}$ Centro de Investigação de Montanha (CIMO), ESA, Instituto Politécnico de Bragança, Campus de Santa Apolónia, apartado 1172, 5301-854 Bragança, Portugal.

${ }^{b}$ Departamento de Nutrición y Bromatología II. Bromatología. Facultad de Farmacia, Universidad Complutense de Madrid (UCM), Plaza Ramón y Cajal s/n, E- 28040 Madrid, Spain.

${ }^{c}$ University of Belgrade, Institute for Biological Research "Siniša Stanković", Department of Plant Physiology, Belgrade, Serbia

* Author to whom correspondence should be addressed (Isabel C.F.R. Ferreira; e-mail: iferreira@ipb.pt; telephone +351-273-303219; fax +351-273-325405).

Running Tittle: Bioaccessibility and antimicrobial activity of phenolic acids and extracts of wild edible mushrooms 


\section{ABSTRACT}

Wild mushrooms are important sources of nutrients and bioactive compounds, namely phenolic acids. After their ingestion, bioactive molecules have to be released from the matrix to be absorbed by the organism. In the present work, two wild edible mushrooms (Volvopluteus gloiocephalus and Clitocybe subconnexa) were studied for their nutritional value, detailed chemical composition and antimicrobial activity. Bioacessibility studies were also performed using the in vitro digestion of the crude powder, phenolic extracts and individual phenolic acids identified in the samples. The studied species proved to be rich sources of nutrients, minerals and bioactive molecules such as phenolic acids. The in vitro digestion conducted to a decrease in antibacterial activity, but not in antifungal and demelanizing properties. Nevertheless, in most of the cases, the analyzed samples presented higher antibacterial and antifungal activities than the standards. The bioactive molecules (phenolic acids) were found in higher concentrations in the phenolic extracts before in vitro digestion, which is agreement with the highest antibacterial activity revealed by these extracts. It should be highlighted that the phenolic acids were still bioavailable after digestion.

Keywords: Wild mushrooms; Chemical composition; Bioaccessibility; Antimicrobial activity 


\section{Introduction}

Mushrooms are known worldwide as being valuable health foods, not only for their unique and subtle flavor, but also for their nutritional properties. The richness in carbohydrates, proteins, fibers, vitamins, and minerals, the presence of unsaturated fatty acids, and the poorness in fat as turned mushrooms in an excellent food choice to include in low caloric diets (Heleno, Barros, Sousa, Martins \& Ferreira, 2010; Kalac, 2012; Reis, Barros, Martins \& Ferreira, 2012).

Furthermore, these organisms are described as functional foods and/or a source of nutraceuticals due to biologically and physiologically active substances such as phenolic acids (Ferreira, Barros \& Abreu, 2009). Mushroom extracts and their phenolic acids have been evaluated regarding antimicrobial activity, showing a very strong antibacterial, antifungal and also demelanizing properties; in several cases, even higher activity than the antibiotics/antifungals frequently used (Alves et al., 2012; Alves et al., 2013; Heleno et al., 2013). Thus, mushrooms could be introduced in our daily diet in order to help the organism in the prevention and combat against microbiological infections, taking advantage of the additive and synergistic effects of all their bioactive compounds (Alves et al., 2013).

Nevertheless, it is important to study the bioaccessibility of these extracts and compounds in order to guarantee the maintenance of the initial bioactivity, since the molecules can suffer structural modifications during the digestion and metabolism, before being absorbed by the intestine (Rodríguez-Roque, Rojas-Graü, Elez-Martínez \& Martín-Belloso, 2013). Several easy and cheap methodologies such as in vitro digestions were developed and are described as being capable of mimetize the in vivo conditions in order to analyse the digestive stability of the food constituents (Bouayed, Hoffmann \& Bohn, 2011). 
In the present work, two wild and edible mushrooms (Volvopluteus gloiocephalus ((DC.) Vizzini, Contu \& Justo) and Clitocybe subconnexa (Murril)) were studied for their nutritional value, detailed chemical composition and antimicrobial activity. To access their bioaccessibility, an in vitro digestion of the crude powder, phenolic extracts and individual phenolic acids identified in the two samples was carried out.

\section{Materials and methods}

\subsection{Samples}

Samples of Volvopluteus gloiocephalus ((DC.) Vizzini, Contu \& Justo) and Clitocybe subconnexa (Murril), two wild edible mushrooms, were collected in Bragança (Northeast Portugal) during November of 2013. After authentications by Dr. Anabela Martins (Polytechnic Institute of Bragança), voucher specimens were deposited at herbarium of School of Agriculture of Polytechnic Institute of Bragança, Portugal. The specimens (for each species, three fruiting bodies in the same maturity stage) were immediately lyophilised (FreeZone 4.5, Labconco, Kansas, USA), reduced to a fine dried powder (20 mesh), mixed to obtain an homogenate sample and kept at $-20{ }^{\circ} \mathrm{C}$ until further analysis.

\subsection{Standards and Reagents}

Acetonitrile $99.9 \%$, n-hexane $95 \%$ and ethyl acetate $99.8 \%$ were of HPLC grade from Fisher Scientific (Lisbon, Portugal). The fatty acids methyl ester (FAME) reference standard mixture 37 (standard 47885-U) was purchased from Sigma (St. Louis, MO, USA), as also other individual fatty acid isomers and standards of sugars (D-(+)mannitol, D-(+)-trehalose), tocopherols ( $\alpha-, \beta$-, and $\gamma$-isoforms), organic acids (oxalic and fumaric acids), phenolic compounds (gallic, $p$-hydroxybenzoic, protocatechuic, 
cinnamic and p-coumaric acids), trolox (6-hydroxy-2,5,7,8-tetramethylchroman-2carboxylic acid), and dietary fiber enzyme kit (TDF-100A Kit), pepsin enzyme (P7000), pancreatin enzyme (P-1750) and porcine bile (B-8631). Racemic tocol, 50 $\mathrm{mg} / \mathrm{mL}$, was purchased from Matreya (PA, USA). Micro (Fe, $\mathrm{Cu}, \mathrm{Mn}$ and $\mathrm{Zn}$ ) and macroelements $\left(\mathrm{Ca}, \mathrm{Mg}, \mathrm{Na}\right.$ and $\mathrm{K}$ ) standards ( $>99 \%$ purity), as well $\mathrm{LaCl}_{2}$ and $\mathrm{CsCl}$

( $>99 \%$ purity) were purchased from Merck (Darmstadt, Germany). Anthrone was obtained from Panreac Química (Barcelona, Spain). Water was treated in a Milli-Q water purification system (TGI Pure Water Systems, Greenville, SC, USA).

\subsection{Chemical composition}

2.3.1. Proximate composition. The samples were analysed for proteins, fat, carbohydrates and ash, using the AOAC procedures (AOAC, 2012). The crude protein content $(\mathrm{N} \times 4.38)$ of the samples was estimated by the macro-Kjeldahl method; the crude fat was determined by the extraction of a known weight of powdered sample with petroleum ether, using a Soxhlet apparatus; the ash and mineral content was determined by incineration at $550 \pm 15^{\circ} \mathrm{C}$.

Total available carbohydrate (TAC) assay was performed by the Anthrone method as described by Osborne \& Voogt (1986) using $0.25 \mathrm{~g}$ of sample. The samples were pretreated with $13 \mathrm{~mL}$ of $\mathrm{HClO}_{4}(52: 100, \mathrm{v} / \mathrm{v})$ and kept for $18 \mathrm{~h}$ in the dark. After this period, distilled water was added, the sample was filtered and the volume of the filtrate was adjusted to $100 \mathrm{~mL}$. Finally, the solution was further diluted to $10 \%$, and $5 \mathrm{~mL}$ of $0.1 \%$ anthrone solution (in $\mathrm{H}_{2} \mathrm{SO}_{4} 73: 100, \mathrm{v} / \mathrm{v}$ ) was added. Samples were kept in a boiling water bath for 12 min where the anthrone reaction with sugars yielded a green colour, and absorbance was measured at $630 \mathrm{~nm}$ on a UV/Vis Spectrometer EZ210 (Perkin Elmer, Waltham, MA, USA) equipped with Lambda software PESSW ver. 1.2. 
The absorbance of the sample solution was compared to a $10-100 \mu \mathrm{g} / \mathrm{mL}$ concentration range standard glucose calibration curve. TAC values were expressed as $\mathrm{g} / 100 \mathrm{~g}$ of dry weight.

AOAC enzymatic-gravimetric methods (993.19 and 991.42) were used for soluble dietary fiber (SDF) and insoluble dietary fiber (IDF) analysis (Latimer, 2012). In brief, freeze-dried samples were treated with alpha-amylase (heat-stable), protease and amyloglucosidase. The soluble and insoluble fractions were separated by vacuum filtration. Waste from the digests was dried at $100{ }^{\circ} \mathrm{C}$. Total fiber is the sum of soluble and insoluble fiber fractions; both were expressed as $\mathrm{g} / 100 \mathrm{~g}$ of dry weight.

Energy was calculated according to the following equation according to Regulation (EC) No. 1169/ 2011 of the European Parliament and of the Council, of 25 October 2011: Energy $(\mathrm{kcal})=4 \times(\mathrm{g}$ protein $+\mathrm{g}$ total available carbohydrate $)+2 \times(\mathrm{g}$ fiber $)+9$ $\times(\mathrm{g}$ fat $)$.

2.3.2. Macro and microelements. Total mineral content (ashes) and mineral elements analysis were performed on dried samples. The method 930.05 of AOAC procedures was used; $500 \mathrm{mg}$ of each sample were subject to dry-ash mineralization at $450^{\circ} \mathrm{C} \pm 15$ ${ }^{\circ} \mathrm{C}$. The residue of incineration was extracted with $\mathrm{HCl}(50 \% \mathrm{v} / \mathrm{v})$ and $\mathrm{HNO}_{3}(50 \% \mathrm{v} / \mathrm{v})$ and made up to an appropriate volume with distilled water, where $\mathrm{Fe}, \mathrm{Cu}, \mathrm{Mn}$ and $\mathrm{Zn}$ were directly measured. An additional $1 / 10(\mathrm{v} / \mathrm{v})$ dilution of the sample extracts and standards was performed to avoid interferences between different elements in the atomic absorption spectroscopy: for $\mathrm{Ca}$ and $\mathrm{Mg}$ analysis in $1.16 \% \mathrm{La}_{2} \mathrm{O}_{3} / \mathrm{HCl}$ (leading to $\mathrm{LaCl}_{2}$ ); for $\mathrm{Na}$ and $\mathrm{K}$ analysis in $0.2 \% \mathrm{CsCl}$ (Ruiz-Rodríguez et al., 2011; FernándezRuiz, Olives Barba, Sanchez-Mata, Camara \& Torija, 2011). All measurements were performed in atomic absorption spectroscopy (AAS) with air/acetylene flame in Analyst 
200 Perkin Elmer equipment (Perkin Elmer, Waltham, MA, USA), comparing absorbance responses with $>99.9 \%$ purity analytical standard solutions for AAS made with $\mathrm{Fe}\left(\mathrm{NO}_{3}\right)_{3}, \mathrm{Cu}\left(\mathrm{NO}_{3}\right)_{2}, \mathrm{Mn}\left(\mathrm{NO}_{3}\right)_{2}, \mathrm{Zn}\left(\mathrm{NO}_{3}\right)_{2}, \mathrm{NaCl}, \mathrm{KCl}, \mathrm{CaCO}_{3}$ and $\mathrm{Mg}$ band. Triplicate mineralization and extractions were carried out on the same material. The results were expressed in mg per $100 \mathrm{~g}$ of dry weight.

2.3.3. Free sugars. Free sugars were determined by a High Performance Liquid Chromatography (HPLC) system consisted of an integrated system with a pump (Knauer, Smartline system 1000, Berlin, Germany), degasser system (Smartline manager 5000) and auto-sampler (AS-2057 Jasco, Easton, MD, USA), coupled to a refraction index detector (RI detector Knauer Smartline 2300) as previously described by the authors (Heleno, Barros, Sousa, Martins \& Ferreira, 2009). Sugars were identified by comparing the relative retention times of sample peaks with standards. Data were analyzed using Clarity 2.4 Software (DataApex, Prague, Czech Republic). Quantification was based on the RI signal response of each standard, using the internal standard (IS, raffinose) method and by using calibration curves obtained from commercial standards of each compound. The results were expressed in g per $100 \mathrm{~g}$ of dry weight.

2.3.4. Fatty acids. Fatty acids were determined after a transesterification procedure as described previously by the authors (Heleno et al., 2009), using a gas chromatographer (DANI 1000, Contone, Switzerland) equipped with a split/splitless injector and a flame ionization detector (GC-FID). Fatty acid identification was made by comparing the relative retention times of FAME peaks from samples with standards. The results were 
recorded and processed using CSW 1.7 software (DataApex 1.7, Prague, Czech Republic). The results were expressed in relative percentage of each fatty acid.

2.3.5. Tocopherols. Tocopherols were determined following a procedure previously described by the authors (Heleno et al., 2010). Analysis was performed by HPLC (equipment described above), and a fluorescence detector (FP-2020; Jasco, Easton, MD, USA) programmed for excitation at $290 \mathrm{~nm}$ and emission at $330 \mathrm{~nm}$. The compounds were identified by chromatographic comparisons with authentic standards. Quantification was based on the fluorescence signal response of each standard, using the IS (tocol) method and by using calibration curves obtained from commercial standards of each compound. The results were expressed in $\mu \mathrm{g}$ per $100 \mathrm{~g}$ of dry weight.

2.3.6. Organic acids. Organic acids were determined following a procedure previously described by the authors (Reis et al., 2013). Analysis was performed by ultra-fast liquid chromatograph (UFLC) coupled to photodiode array detector (PDA), using a Shimadzu 20A series UFLC (Shimadzu Corporation, Kyoto, Japan). Detection was carried out in a PDA, using $215 \mathrm{~nm}$ and 245 as preferred wavelengths. The organic acids were quantified by comparison of the area of their peaks recorded at $215 \mathrm{~nm}$ with calibration curves obtained from commercial standards of each compound. The results were expressed in g per $100 \mathrm{~g}$ of dry weight.

\subsection{In vitro gastrointestinal model (dialysis) for bioaccessibility studies}

Bioaccessibility was determined using $25 \mathrm{~mL}$ of aqueous solutions prepared from dry mushrooms powder $(20 \mathrm{mg} / \mathrm{mL})$, phenolic extracts $(50 \mathrm{mg} / \mathrm{mL})$ and phenolic acids $(1$ $\mathrm{mg} / \mathrm{mL}$ ). The phenolic extracts were previously prepared by extracting twice $1.5 \mathrm{~g}$ of 
dry mushroom powder with methanol:water $(80: 20, v / v ; 30 \mathrm{~mL})$ at $-20^{\circ} \mathrm{C}$ for $1.5 \mathrm{~h}$; after a sonication step for $15 \mathrm{~min}$, the extracts were filtered through Whatman No. 4 paper and dried (Barros, Dueñas, Ferreira, Baptista \& Santos-Buelga, 2009).

The gastric digestion was simulated (Ramírez-Moreno, Marquês, Sánchez-Mata \& Goñi, 2011; Heleno et al., 2015), adjusting the $\mathrm{pH}$ of each sample to 2, adding $150 \mathrm{~mL}$ of a pepsin solution $(40 \mathrm{mg} / \mathrm{mL}$ of $\mathrm{HCl} 0.1 \mathrm{M})$, and incubating the mixture in a water bath at $37^{\circ} \mathrm{C}$ for $2 \mathrm{~h}$ with stirring (60 osc/min). The intestinal digestion was then simulated, adding to the mentioned mixture a pancreatin/bile solution $(5 / 25 \mathrm{mg}$ of pancreatin/bile per $1 \mathrm{~mL}$ of baking soda $0.1 \mathrm{M}$ ). The mixture was then transferred to dialysis membranes, previously boiled in distilled water for $15 \mathrm{~min}$. The dialysis membranes/mixture was then placed in to a flask containing $250 \mathrm{~mL}$ of baking soda $\mathrm{pH}$ 7.5 and incubated in a water bath at room temperature for $3 \mathrm{~h}$ with stirring ( $60 \mathrm{osc} / \mathrm{min})$. After dialysis, the obtained final solution of baking soda $\mathrm{pH} 7.5$ was frozen and lyophilized for evaluation of antimicrobial and demelanizing activity, and analysis of phenolic compounds.

\subsection{Antimicrobial activity}

Antibacterial activity was evaluated against Gram-negative bacteria: Escherichia coli (ATCC 35210), Pseudomonas aeruginosa (ATCC 27853), Salmonella typhimurium (ATCC 13311), Enterobacter cloacae (ATCC 35030), and Gram-positive bacteria: Staphylococcus aureus (ATCC 6538), Bacillus cereus (clinical isolate), Micrococcus flavus (ATCC 10240), and Listeria monocytogenes (NCTC 7973), following the procedure previously described by the authors (Soković, Glamočlija, Marin, Brkić \& van Griensven, 2010). The minimum inhibitory (MIC) and minimum bactericidal (MBC) concentrations were determined following the same reference. Streptomycin and 
ampicillin were used as positive controls ( $1 \mathrm{mg} / \mathrm{mL}$ in sterile physiological saline). Antifungal activity was evaluated against Aspergillus fumigatus (ATCC 1022), Aspergillus ochraceus (ATCC 12066), Aspergillus versicolor (ATCC 11730), Aspergillus niger (ATCC 6275), Penicillium funiculosum (ATCC 36839), Penicillium ochrochloron (ATCC 9112), Trichoderma viride (IAM 5061), and Penicillium verrucosum var. cyclopium (food isolate), following the procedure previously described by the authors (Soković \& van Griensven, 2006). The minimum inhibitory (MIC) and minimum fungicidal (MFC) concentrations were determined following the same reference. 5\% DMSO (solvent) was used as negative control. Bionazole and ketokonazole were used as positive controls $(1-3000 \mu \mathrm{g} / \mathrm{mL})$. The microorganisms were obtained from the Mycological Laboratory, Department of Plant Physiology, Institute for Biological Research 'Siniša Stankovic', Belgrade, Serbia.

\subsection{Demelanizing activity using micromycetes}

All the microfungi tested for antifungal activity were used to evaluate the demelanizing activity of all the samples before and after in vitro digestion. The micromycetes were maintained on malt agar and the cultures were stored at $4^{\circ} \mathrm{C}$. The fungal spores were submitted to the procedures previously described by the authors (Heleno et al., 2014). Determination of minimum demelanizing concentrations (MDC; the lowest concentration that provoked demelanization of fungal hyphae and conidia) was performed by a serial dilution technique. Samples from the control plate without added extracts were also stained and observed. Solution of 5\% DMSO was used as a negative control.

\subsection{Phenolic compounds analysis}


The phenolic extracts were submitted to a liquid-liquid extraction with diethyl ether (2 x $20 \mathrm{~mL})$ and ethyl acetate $(2 \times 20 \mathrm{~mL})$. Anhydrous sodium sulphate was added to the combined organic phases and the extracts were filtrated through Whatman No. 4 paper, evaporated to dryness and re-dissolved in methanol:water $(20: 80, \mathrm{v} / \mathrm{v})$. The extracts $(1$ ml) were filtered through a $0.22 \mu \mathrm{m}$ disposable LC filter disk. Phenolic acids determination was performed using a Shimadzu 20A series ultra-fast liquid chromatograph (UFLC, Shimadzu, equipment described above) as previously described by Reis et al. (2013). Detection was carried out in a photodiode array detector (PDA), using $280 \mathrm{~nm}$ as the preferred wavelength. The phenolic compounds were quantified by comparison of the area of their peaks recorded at $280 \mathrm{~nm}$ with calibration curves obtained from commercial standards of each compound. The results were expressed in $\mu \mathrm{g}$ per $100 \mathrm{~g}$ of dry weight.

\subsection{Statistical analysis}

Three samples were used for each preparation and all the assays were carried out in triplicate. The results are expressed as mean values and standard deviation (SD). In the case of proximate composition, free sugars, fatty acids, tocopherols, organic acids and minerals a student's $t$-test was used because there were less than three groups. This treatment was carried out using SPSS v. 22.0 program.

\section{Results and discussion}

\subsection{Chemical composition}

The results concerning the proximate composition, free sugars and fatty acids of $V$. gloiocephalus and C. subconnexa are presented in Table 1. For both species, total dietary fiber (TDF) was the most abundant macronutrient, followed by proteins in $V$. 
gloiocephalus, and total available carbohydrates (TAC) in C. subconnexa. Insoluble dietary fiber (IDF) predominated over soluble dietary fiber (SDF), which is in agreement with the existing reports in the literature (Kalac, 2012; Heleno et al., 2015). C. subconnexa revealed much higher contents in TAC contributing to the higher energetic value of this species, but presented lower amounts in proteins and fat.

Mannitol and trehalose were identified and quantified in both samples, but in higher concentration in C. subconnexa, especially mannitol, that contributed to the higher amount in total free sugars revealed by this species in which fructose was also found. Regarding the fatty acids, polyunsaturated fatty acids (PUFA) predominated over monounsaturated (MUFA) and saturated (SA) fatty acids due to the high contribution of linoleic acid (Table 1). The contents in palmitic and stearic acids were similar in both samples, whereas the contents in oleic acid were significantly higher in C. subconnexa, contributing to its higher amounts in MUFA. On the other hand, the contents in linoleic acids were higher in $V$. gloiocephalus, contributing to its higher amounts PUFA.

Concerning the tocopherols, $\alpha$ isoform was quantified in both samples, but in higher levels in $V$. gloiocephalus. Gamma- and beta-compounds were only found in this sample, contributing to its higher amounts of total tocopherols (Table 2). Oxalic and fumaric acids were identified in both samples, but in higher concentration in $C$. subconnexa.

Mineral elements (macro and microelements) were identified in both samples (Table 3). The macroelement $\mathrm{K}$ was the most abundant, followed by $\mathrm{Na}, \mathrm{Mg}$ and finally $\mathrm{Ca}$ in both samples. Regarding the microelements, Fe was the most abundant, followed by $\mathrm{Zn}, \mathrm{Cu}$ and $\mathrm{Mn}$ also in both samples. These results are in agreement with the reported in literature describing $\mathrm{K}$ as the major macroelement found in mushrooms (Mattila et al., 2001). V. gloiocephalus revealed much higher contents in $\mathrm{K}$ and Fe probably due to the 
accumulation of these components caused by the adaptation to environmental condition (Kalac, 2012).

To the author's knowledge, this is the first report on the nutritional value and chemical characterization of $V$. gloiocephalus.

3.2. Bioaccessibility studies and antimicrobial activity of phenolic extracts (before and after in vitro digestion), and of in vitro digested mushrooms

The phenolic extracts of $V$. gloiocephalus and $C$. subconnexa showed higher antibacterial activity than the in vitro digested samples (either mushrooms or phenolic extracts; Table 4) that presented a similar behavior. Nevertheless, all the tested samples revealed higher antibacterial activity than ampicillin and, in almost of the cases, also higher than streptomycin. Staphylococcus aureus was the most susceptible bacteria to $V$. gloiocephalus phenolic extract, while Salmonella typhimurium was the most susceptible one to the in vitro digested samples (mushroom and phenolic extract). Bacillus cereus and S. typhimurium were the most sensitive bacteria to $C$. subconnexa phenolic extract; the in vitro digested mushroom presented the highest activity against $P$. aeruginosa and S. typhimurium; $P$. aeruginosa was also susceptible to the in vitro digested phenolic extract. $S$. typhimurium revealed to be the most sensitive bacteria to the tested samples, whereas Micrococcus flavus showed the highest resistance.

Regarding antifungal activity, the in vitro digested samples showed similar behavior (Table 4). $V$. gloiocephalus phenolic extract gave higher activity than digested samples, while the opposite was observed for C. subconnexa. All the samples exhibited higher antifungal activity than ketoconazole and, in almost of the cases, also than bifonazole. Aspergillus ochraceus and Penicillium funiculosum were the most susceptible fungi to V. gloiocephalus phenolic extract. A. ochraceus and Trichoderma viride were the most 
sensitive to the in vitro digested mushroom. The in vitro digested phenolic extract was more efficient against $T$. viride and $P$. funiculosum. Regarding $C$. subconnexa, the phenolic extract was more effective against T. viride and P. funiculosum. A. ochraceus and $T$. viride were the most sensitive fungi to the in vitro digested mushroom. The in vitro digested phenolic extract was more effective against $T$. viride, $P$. ochrochloron and $P$. verrucosum. $T$. viride was the most susceptible fungi to the tested samples while the fungi belonging to the Aspergillus genus revealed the highest resistance (Table 4). The phenolic acids identified in $V$. gloiocephalus and C. subconnexa extracts before and after in vitro digestion, and also in digested mushrooms are presented in Table 5. The phenolic extracts (before in vitro digestion) revealed the highest content in all the identified compounds, followed by the in vitro digested phenolic extracts. The in vitro digested mushrooms presented the lowest content, maybe due to the presence of phenolic compounds linked to other molecules (e.g., polysaccharides), that difficult the cross of the dialysis membrane (Bermúdez-Soto, Tomás-Barberán \& García-Conesa, 2007; Rodríguez-Roque et al., 2013). However, it should be highlighted that the identified compounds are still bioavailable after digestion, although they are present in lower contents.

\subsection{Bioaccessibility studies and antimicrobial activity of individual phenolic acids} before and after in vitro digestion

Among the individual phenolic acids analyzed before in vitro digestion, cinnamic acid (CA) was the most active against all the bacteria, followed by $p$-hydroxybenzoic (HA) and p-coumaric (CoA) acids (Table 6). Gallic (GA) and protocatechuic (PA) acids showed the lowest antibacterial activity. Nevertheless, the phenolic acids revealed higher activity than ampicillin and streptomycin, against almost all the tested bacteria. 
B. cereus was the most susceptible bacteria to the individual phenolic acids. After in vitro digestion, $p$-hydroxybenzoic (DHA) and protocatechuic (DPA) acids gave the highest antibacterial activity, followed by $p$-coumaric (DCoA) and cinnamic (DCA) acids; gallic acid (DGA) gave the lowest activity (Table 6). P. aeruginosa was the most sensitive bacteria to the in vitro digested phenolic acids, being $M$. flavus the most resistant one. A decrease in the phenolic acids antibacterial activity was observed after in vitro digestion, which is in agreement with other reports describing structural modifications of the bioactive molecules due to the drastic $\mathrm{pH}$ variation (BermúdezSoto et al., 2007; Rodríguez-Roque et al., 2013). Still, the in vitro digested phenolic acids maintained a higher antibacterial activity than ampicillin and also than streptomycin against most of the bacteria (Table 6).

Among the individual phenolic acids, CA revealed the highest antifungal activity, followed by GA, PA and HA, with CoA presenting the lowest activity. A. ochraceus and $T$. viride were the most susceptible fungi to the individual phenolic acids, being $A$. niger and A. fumigatus the most resistant ones. The samples exhibited higher activity than the two standards used in the majority of the cases. For the in vitro digested phenolic acids, their antifungal activity was very similar. The most susceptible bacteria were A. ochraceus and T. viride, while A. niger was the most resistant one, as for the individual phenolic acids before digestion. The antifungal activity of the tested compounds was maintained after digestion, with the exception of DHA and DCA that presented lower activity. However, the in vitro digested phenolic acids also exhibited stronger antifungal activity than the standards, against the majority of the fungi (Table 6).

The demelanizing activity of the extracts and individual compounds was tested toward the same eight microfungi used for the antifungal assays. All the tested samples 
revealed demelanizing properties but acting in different proportions against the different fungi. The phenolic extracts and individual phenolic acids showed the highest demelanizing abilities, presenting the in vitro digested samples a very similar behavior (Data not shown) to the one observed for the antifungal properties. Gallic acid was the most active compound; its effects were significant on $A$. fumigatus, A. niger, $P$. funiculosum, and P. verrucosum var. cyclopium (Figure 1). This compound provoked demelanizing effect on $A$. fumigatus, by lowering the amount of conidia and giving nude vesicle without conidia (Figure 1A-C). On A. niger, gallic acid reduced the number of spores and vesicles, and at higher concentrations it completely reduced spores and induced thinner hyphae (Figure 1D-F). Furthermore, this compound also reduced the number of spores on P. funiculosum and nude heads, and increasing the concentration, the hyphae became tiny and short (Figure 1C-J). On P. ochrochloron, besides reducing the number of spores (Figure $\mathbf{1 K}, \mathbf{L}$ ), this compound provoked fialides without conidia (Figure 1M, N). Changes in both Aspergillus and Penicillium species are obvious and can be described as depigmentation, morphological changes of conidiphores-unusually small, number of heads and nude vesicles and fialides, when compared with control mycelium's (Figure 1A-N). The colored conidiophores of some Aspergillus and Penicillium species contain melanin that contribute to the virulence of pathogens of humans as well as those of food crops (Rosa, Vieira, Santiago \& Rosa, 2010). Previous studies of demelanization activity of different mushroom extracts (Ganoderma lucidum and Coprinopsis atramentaria) showed strong effects on few microfungi, namely A. niger (Heleno et al. 2013; Heleno et al. 2014).

\section{Conclusion}


As far as we know this is the first report on the chemical characterization, antimicrobial activity and bioaccessibility of $V$. gloiocephalus and $C$. subconnexa mushrooms, extracts and phenolic acids. Although being low caloric foods (with low fat content and prevalence of PUFA), these two species proved to be rich sources of carbohydrates (e.g., fibers), proteins, minerals and also bioactive compounds (e.g., phenolic compounds and tocopherols). Regarding the antimicrobial activity, the phenolic extracts of $V$. gloiocephalus and $C$. subconnexa revealed higher activity than the in vitro digested samples (mushrooms or phenolic extracts); the observed antimicrobial activity decrease might be attributed to structural modifications caused by drastic $\mathrm{pH}$ variations and to the presence of phenolic acids linked to other molecules that difficult the cross through dialysis membrane. No significant differences were observed for the antifungal and demelanizing activities. CA was the most active phenolic acid against all the bacteria and also against fungi. It should be highlighted that, for almost all the cases, the analyzed samples presented higher antibacterial and antifungal activities than the standards. The concentration of the bioactive molecules (phenolic acids) decreased after in vitro digestion, which is agreement with the decrease observed for antibacterial activity. Nevertheless, the phenolic acids were still bioavailable, although in lower amounts.

\section{Acknowledgements}

The authors are grateful to Fundação para a Ciência e a Tecnologia (FCT, Portugal) for financial support to CIMO (strategic project PEst-OE/AGR/UI0690/2011) and ALIMNOVA research group (UCM-GR35/10A). S.A. Heleno thanks to FCT for the grant (BD/70304/2010) and L. Barros contract under "Programa Compromisso com a Ciência-2008".

\section{References}


Alves, M.J., Ferreira, I.C.F.R., Dias, J., Teixeira, V., Martins, A., \& Pintado, M. (2012). A Review on Antimicrobial Activity of Mushroom (Basidiomycetes) Extracts and Isolated Compounds. Planta Medica, 78, 1707-1718.

Alves, M.J., Ferreira, I.C.F.R., Froufe, H.J.C., Abreu, R.M.V., Martins, A., \& Pintado, M. (2013). Antimicrobial activity of phenolic compounds identified in wild mushrooms, SAR analysis and docking studies. Journal of Applied Microbiology, $115,346-357$.

AOAC. (2012). Official methods of analysis of AOAC INTERNATIONAL. (19 ${ }^{\text {th }}$ ed.). Gaithersburg, MD, USA: AOAC INTERNATIONAL.

Barros, L., Dueñas, M., Ferreira, I.C.F.R., Baptista, P., \& Santos-Buelga, C. (2009). Phenolic acids determination by HPLC-DAD-ESI/MS in sixteen different Portuguese wild mushrooms species. Food and Chemical Toxicology, 47, 10761079 .

Bermúdez-Soto, M.A., Tomás-Barberán, F.A., \& García-Conesa, M.T. (2007). Stability of polyphenols in chokeberry (Aronia melanocarpa) subjected to in vitro gastric and pancreatic digestion. Food Chemistry, 102, 865-874.

Bouayed, J., Hoffmann, L., \& Bohn, T. (2011). Total phenolics, flavonoids, anthocyanins and antioxidant activity following simulated gastro-intestinal digestion and dialysis of apple varieties: Bioaccessibility and potential uptake. Food Chemistry, 128, 14-21.

Fernández-Ruiz, V., Olives Barba, A.I., Sanchez-Mata, M.C., Camara, M., \& Torija, M.E. (2011). Mineral and Trace Elements Content in 30 Accessions of Tomato Fruits (Solanum lycopersicum L.,) and Wild Relatives (Solanum pimpinellifolium L., Solanum cheesmaniae L. Riley, and Solanum habrochaites S. Knapp \& D.M. Spooner). Biological Trace Element Research, 141, 329-339. 
Ferreira, I.C.F.R., Barros, L., \& Abreu, R.M.V. (2009). Antioxidant in Wild mushrooms. Current Medicinal Chemistry, 16, 1543-1560.

Heleno, S.A., Barros, L., Martins, A., Queiroz, M.J.R.P., Morales, P., Fernández-Ruiz, V., \& Ferreira, I.C.F.R. (2015). Chemical composition, antioxidant activity and bioaccessibility studies in phenolic extracts of two Hericium wild edible species, LWT - Food Science and Technology, in press, doi: 10.1016/j.lwt.2015.03.040.

Heleno, S.A., Barros, L., Sousa, M.J., Martins, A., \& Ferreira, I.C.F.R. (2009). Study and characterization of selected nutrients in wild mushrooms from Portugal by gas chromatography and high performance liquid chromatography. Microchemical Journal, 93,195-199.

Heleno, S.A., Barros, L., Sousa, M.J., Martins, A., \& Ferreira, I.C.F.R. (2010). Tocopherols composition of Portuguese wild mushrooms with antioxidant capacity. Food Chemistry, 119, 1443-1450.

Heleno, S.A., Ferreira, I.C.F.R., Ciric, A., Glamoclija, J., Martins, A., Queiroz, M.J.R.P., \& Sokovic, M. (2014). Coprinopsis atramentaria extract, its organic acids, and synthesized glucuronated and methylated derivatives as antibacterial and antifungal agents. Food \& Function, 5, 2521-2528.

Heleno, S.A., Ferreira, I.C.F.R., Esteves, A.P., Ciric, A., Glamoclija, J., Martins. A., Sokovic, M., \& Queiroz, M.-J.R.P. (2013). Antimicrobial and demelanizing activity of Ganoderma lucidum extract, p-hydroxybenzoic and cinnamic acids and their synthetic acetylated glucuronide methyl esters. Food and Chemical Toxicology, 58, 95-100.

Kalac, P. (2012). Chemical composition and nutritional value of European species of wild growing mushrooms, In Mushrooms: types, properties and nutrition. Editors: S. Andres and N. Baumann. Nova Science Publishers, 130-151. 
Latimer, G.W. (2012). Official methods of analysis of AOAC international (18th ed.). Gaithersburg: EEUU.

Mattila, P., Konko, K., Eurola, M., Pihlava, J. M., Astola, J., Vahteristo, L., Hietaniemi, V., Kumpulainen, J., Valtonen, M., \& Piironen, V. (2001). Contents of vitamins, mineral elements, and some phenolic compounds in cultivated mushrooms. Journal of Agricultural and Food Chemistry, 49, 2343-2348.

Osborne, D.R., \& Voogt, P. (1986). Análisis de los nutrientes de los alimentos. (pp. 258). Zaragoza: Ed. Acribia.

Ramírez-Moreno, E., Marquês, C.D., Sánchez-Mata, M.C., \& Goñi, I. (2011). In vitro calcium bioaccessibility in raw and cooked cladodes of prickly pear cactus (Opuntia ficus-indica L. Miller). LWT - Food Science and Technology, 44, 16111615.

Reis, F.S., Barros, L., Martins, A., \& Ferreira, I.C.F.R. (2012). Chemical composition and nutritional value of the most widely appreciated cultivated mushrooms: An inter-species comparative study. Food and Chemical Toxicology, 50, 191-197.

Reis, F.S., Barros, L., Calhelha, R.C., Cirić, A., van Griensven, L.J., Soković, M., \& Ferreira, I.C.F.R. (2013). The methanolic extract of Cordyceps militaris (L.) Link fruiting body shows antioxidant, antibacterial, antifungal and antihuman tumor cell lines properties. Food Chemical and Toxicology, 62, 91-98.

Rodríguez-Roque, M.J., Rojas-Graü, M.A., Elez-Martínez, P., \& Martín-Belloso, O. (2013). Soymilk phenolic compounds, isoflavones and antioxidant activity as affected by in vitro gastrointestinal digestion. Food Chemistry, 136, 206-212.

Rosa, L.H., Vieira, L.M.A., Santiago, I.F., \& Rosa, C.A. (2010). Endophytic fungi community associated with the dicotyledonous plant Colobanthus quitensis 
(Kunth) Bartl. (Caryophyllaceae) in Antarctica. FEMS Microbiology Ecology, 73, 178-189.

Ruiz-Rodríguez, B., Morales, P., Fernández-Ruiz, V., Sánchez-Mata, M.C., Cámara, M., Díez-Marqués, C., Santayana, M.P., Molina, M., \& Tardío, J. (2011). Valorization of wild strawberry tree fruits (Arbutus unedo L.) through nutritional assessment and natural production data. Food Research International, 44, 12441253.

Soković, M., \&. van Griensven L.J.L.D (2006). Antimicrobial activity of essential oils and their components against the three major pathogens of the cultivated button mushroom, Agaricus bisporus. European Journal of Plant Pathology, 116, 211224.

Soković, M., Glamočlija, J., Marin D. P., Brkić, D., \& van Griensven, L.J.L.D. (2010). Antibacterial effects of the essential oils of commonly consumed medicinal herbs using an in vitro model. Molecules, 15, 7532-7546. 
Table 1. Proximate composition, free sugars and fatty acids in Volvopluteus gloiocephalus ((DC.) Vizzini, Contu \& Justo) and Clitocybe subconnexa (Murril).

\begin{tabular}{llll}
\hline Parameter & $\begin{array}{l}\text { Volvopluteus } \\
\text { gloiocephalus }\end{array}$ & $\begin{array}{l}\text { Clitocybe } \\
\text { subconnexa }\end{array}$ & $\begin{array}{l}\text { Student's } t \text {-test } \\
\text {-value }\end{array}$ \\
\hline Ash (g/100 g dw) & $14.19 \pm 0.07$ & $5.98 \pm 0.04$ & $<0.001$ \\
Total available carbohydrates & $13.97 \pm 0.34$ & $27.35 \pm 0.13$ & $<0.001$ \\
Total Dietary Fiber & $39.12 \pm 0.29$ & $38.74 \pm 0.79$ & 0.538 \\
$\quad$ Insoluble fibre & $37.08 \pm 0.26$ & $36.42 \pm 1.19$ & 0.003 \\
$\quad$ Soluble fibre & $2.04 \pm 0.03$ & $3.35 \pm 0.36$ & 0.394 \\
Proteins (g/100 g dw) & $19.66 \pm 0.14$ & $7.42 \pm 0.25$ & $<0.001$ \\
Fat (g/100 g dw) & $4.62 \pm 0.04$ & $1.02 \pm 0.09$ & $<0.001$ \\
Energy (kcal/100 g dw) & $366.34 \pm 0.05$ & $381.18 \pm 0.23$ & $<0.001$ \\
\hline Fructose & $\mathrm{nd}$ & $0.72 \pm 0.03$ & - \\
Mannitol & $1.45 \pm 0.10$ & $24.71 \pm 0.55$ & $<0.001$ \\
Trehalose & $1.92 \pm 0.11$ & $6.00 \pm 0.01$ & $<0.001$ \\
Total Sugars (g/100 g dw) & $3.37 \pm 0.21$ & $30.71 \pm 0.56$ & $<0.001$ \\
\hline C16:0 & $7.42 \pm 0.17$ & $7.31 \pm 0.17$ & 0.322 \\
C18:0 & $2.09 \pm 0.07$ & $2.15 \pm 0.08$ & 0.205 \\
C18:1n9c & $25.96 \pm 0.02$ & $42.50 \pm 1.19$ & $<0.001$ \\
C18:2n6c & $59.33 \pm 0.15$ & $44.88 \pm 0.66$ & $<0.001$ \\
\hline SFA (percent) & $12.56 \pm 0.17$ & $11.00 \pm 0.46$ & 0.001 \\
MUFA (percent) & $26.47 \pm 0.01$ & $43.45 \pm 1.23$ & $<0.001$ \\
PUFA (percent) & $60.97 \pm 0.17$ & $45.59 \pm 0.76$ & $<0.001$ \\
\hline
\end{tabular}

dw- dry weight; Palmitic acid (C16:0); Stearic acid (C18:0); Oleic acid (C18:1n9c); Linoleic acid (C18:2n6c). SFA- saturated fatty acids; MUFA- monounsaturated fatty acids; PUFA- polyunsaturated fatty acids. The difference to $100 \%$ corresponds to other 23 less abundant fatty acids (data not shown). 
Table 2. Tocopherols and organic acids in Volvopluteus gloiocephalus ((DC.) Vizzini, Contu \& Justo) and Clitocybe subconnexa (Murril).

\begin{tabular}{llll}
\hline Compound & $\begin{array}{l}\text { Volvopluteus } \\
\text { gloiocephalus }\end{array}$ & $\begin{array}{l}\text { Clitocybe } \\
\text { Subconnexa }\end{array}$ & $\begin{array}{l}\text { Students } t \text {-test } \\
p \text {-value }\end{array}$ \\
\hline$\alpha$-Tocopherol & $13.83 \pm 0.65$ & $6.98 \pm 0.56$ & $<0.001$ \\
$\beta$-Tocopherol & $66.06 \pm 2.31$ & n.d. & - \\
$\gamma$-Tocopherol & $20.20 \pm 2.74$ & n.d. & - \\
Total tocopherols $(\mu \mathrm{g} / 100 \mathrm{~g} \mathrm{dw})$ & $100.09 \pm 0.21$ & $6.98 \pm 0.56$ & $<0.001$ \\
\hline Oxalic acid & $0.37 \pm 0.03$ & $2.64 \pm 0.07$ & $<0.001$ \\
Fumaric acid & $0.13 \pm 0.01$ & $0.23 \pm 0.01$ & $<0.001$ \\
Total organic acids $(\mathrm{g} / 100 \mathrm{~g} \mathrm{dw})$ & $0.50 \pm 0.03$ & $2.87 \pm 0.07$ & $<0.001$ \\
dw- dry weight. n.d.- not detected & & &
\end{tabular}


Table 3. Macro and microelements in Volvopluteus gloiocephalus ((DC.) Vizzini, Contu \& Justo) and Clitocybe subconnexa (Murril).

\begin{tabular}{llll}
\hline & $\begin{array}{l}\text { Volvopluteus } \\
\text { gloiocephalus }\end{array}$ & $\begin{array}{l}\text { Clitocybe } \\
\text { Subconnexa }\end{array}$ & $\begin{array}{l}\text { Student's } t \text {-test } \\
p \text {-value }\end{array}$ \\
\hline Macroelements (mg/100 g dw) & & & \\
\hline $\mathrm{Ca}$ & $73.52 \pm 5.54$ & $92.68 \pm 0.96$ & $<0.001$ \\
$\mathrm{Mg}$ & $200.19 \pm 14.57$ & $148.86 \pm 1.36$ & $<0.001$ \\
$\mathrm{Na}$ & $790.56 \pm 67.26$ & $722.04 \pm 23.37$ & 0.137 \\
$\mathrm{~K}$ & $4692.55 \pm 64.43$ & $2023.25 \pm 156.75$ & $<0.001$ \\
\hline $\mathrm{Microelements}(\mathrm{mg} / 100 \mathrm{~g} \mathrm{dw})$ & & & \\
\hline $\mathrm{Fe}$ & $69.91 \pm 6.89$ & $6.53 \pm 0.18$ & $<0.001$ \\
$\mathrm{Cu}$ & $5.01 \pm 0.44$ & $5.22 \pm 0.05$ & 0.997 \\
$\mathrm{Mn}$ & $0.13 \pm 0.01$ & $0.10 \pm 0.01$ & 0.882 \\
$\mathrm{Zn}$ & $10.89 \pm 0.12$ & $6.37 \pm 0.64$ & $<0.001$ \\
\hline
\end{tabular}

dw- dry weight. 
Table 4. Antimicrobial activity (MIC followed by MBC or MFC, $\mu \mathrm{g} / \mathrm{mL}$ ) of mushroom phenolic extracts before and after in vitro digestion, and of in vitro digested mushrooms.

\begin{tabular}{|c|c|c|c|c|c|c|c|c|}
\hline \multirow[b]{3}{*}{ Bacteria } & \multicolumn{3}{|c|}{ Volvopluteus gloiocephalus } & \multicolumn{3}{|c|}{ Clitocybe subconnexa } & \multicolumn{2}{|c|}{ Standards } \\
\hline & Before in vitro digestion & After in & ro digestion & Before in vitro digestion & After $i$ & ro digestion & & \\
\hline & Extract & Mushroom & Extract & Extract & Mushroom & Extract & Ampicillin & Streptomycin \\
\hline Staphylococcus & 40 & 150 & 150 & 100 & 150 & 150 & 240 & 40 \\
\hline aureus & 50 & 290 & 290 & 210 & 290 & 290 & 400 & 80 \\
\hline Bacillus & 50 & 150 & 150 & 50 & 150 & 150 & 240 & 80 \\
\hline cereus & 100 & 290 & 290 & 100 & 290 & 290 & 400 & 160 \\
\hline Micrococcus & 100 & 170 & 150 & 150 & 210 & 150 & 240 & 160 \\
\hline flavus & 210 & 330 & 290 & 210 & 420 & 290 & 400 & 320 \\
\hline Listeria & 100 & 150 & 150 & 100 & 150 & 150 & 400 & 160 \\
\hline monocytogenes & 210 & 290 & 290 & 210 & 290 & 290 & 480 & 320 \\
\hline Pseudomonas & 50 & 100 & 100 & 70 & 90 & 90 & 800 & 160 \\
\hline aeruginosa & 100 & 210 & 210 & 100 & 190 & 190 & 1280 & 320 \\
\hline Salmonella & 50 & 90 & 90 & 50 & 90 & 90 & 400 & 160 \\
\hline typhimurium & 210 & 190 & 190 & 100 & 190 & 210 & 480 & 320 \\
\hline Escherichia & 100 & 150 & 150 & 100 & 170 & 150 & 240 & 160 \\
\hline coli & 210 & 290 & 290 & 210 & 330 & 290 & 480 & 320 \\
\hline Enterobacter & 100 & 100 & 150 & 150 & 100 & 150 & 400 & 400 \\
\hline cloacae & 210 & 210 & 290 & 210 & 210 & 290 & 800 & 800 \\
\hline Fungi & Extract & Mushroom & Extract & Extract & Mushroom & Extract & Bifonazole & Ketoconazole \\
\hline Aspergillus & $63 \pm 10^{b}$ & 73 & 73 & 125 & 73 & 73 & 150 & 200 \\
\hline fumigatus & $208 \pm 40$ & 146 & 146 & 167 & 146 & 146 & 200 & 500 \\
\hline Aspergillus & $42 \pm 10$ & 52 & 63 & 83 & 57 & 63 & 150 & 150 \\
\hline ochraceus & $83 \pm 20^{c}$ & 104 & 125 & 168 & 115 & 125 & 200 & 200 \\
\hline Aspergillus & $42 \pm 10^{\mathrm{b}}$ & 73 & 73 & 208 & 73 & 63 & 100 & 200 \\
\hline versicolor & $125 \pm 10^{\mathrm{b}}$ & 146 & 146 & 350 & 146 & 125 & 200 & 500 \\
\hline Aspergillus & $167 \pm 40^{\mathrm{a}}$ & 73 & 73 & 167 & 73 & 73 & 150 & 200 \\
\hline niger & $317 \pm 40^{\mathrm{a}}$ & 146 & 146 & 300 & 146 & 146 & 200 & 500 \\
\hline Trichoderma & $26 \pm 10^{b}$ & 57 & 57 & 68 & 57 & 57 & 150 & 1000 \\
\hline viride & $125 \pm 10^{\mathrm{a}}$ & 115 & 115 & 94 & 115 & 115 & 200 & 1500 \\
\hline Penicillium & $42 \pm 10^{\mathrm{b}}$ & 63 & 57 & 73 & 63 & 63 & 200 & 200 \\
\hline funiculosum & $83 \pm 20^{c}$ & 125 & 115 & 104 & 125 & 125 & 250 & 500 \\
\hline Penicillium & $42 \pm 10^{\mathrm{b}}$ & 63 & 63 & 83 & 63 & 57 & 200 & 1000 \\
\hline ochrochloron & $125 \pm 10$ & 125 & 125 & 125 & 125 & 115 & 250 & 1500 \\
\hline Penicillium & $42 \pm 10^{\mathrm{b}}$ & 63 & 63 & 83 & 63 & 57 & 200 & 1500 \\
\hline verrucosum & $125 \pm 10$ & 125 & 125 & 125 & 125 & 115 & 300 & 2000 \\
\hline
\end{tabular}


MIC- minimal inhibitory concentrations; MBC- minimal bactericidal concentrations; MFC- minimal fungicidal concentrations. 
Table 5. Phenolic acids ( $\mu \mathrm{g} / 100 \mathrm{~g} \mathrm{dw})$ in Volvopluteus gloiocephalus and Clitocybe subconnexa (phenolic extract and mushrooms) before and after in vitro digestion.

\begin{tabular}{|c|c|c|c|c|c|c|}
\hline \multirow[b]{3}{*}{ Phenolic compounds } & \multicolumn{3}{|c|}{ Volvopluteus gloiocephalus } & \multicolumn{3}{|c|}{ Clitocybe subconnexa } \\
\hline & \multirow{2}{*}{$\begin{array}{c}\text { Before in vitro digestion } \\
\text { Phenolic extract }\end{array}$} & \multicolumn{2}{|c|}{ After in vitro digestion } & \multirow{2}{*}{$\begin{array}{c}\text { Before in vitro digestion } \\
\text { Phenolic extract }\end{array}$} & \multicolumn{2}{|c|}{ After in vitro digestion } \\
\hline & & Mushroom & Phenolic extract & & Mushroom & Phenolic extract \\
\hline Gallic acid & $74.15 \pm 3.46^{\mathrm{a}}$ & $20.08 \pm 0.89^{\mathrm{c}}$ & $60.88 \pm 2.84^{b}$ & $55.62 \pm 1.43^{\mathrm{a}}$ & $12.33 \pm 0.15^{\mathrm{c}}$ & $24.62 \pm 0.58^{b}$ \\
\hline$p$-Hydroxybenzoic acid & $85.59 \pm 4.86^{\mathrm{a}}$ & $3.40 \pm 0.05^{\mathrm{c}}$ & $62.96 \pm 2.71^{\mathrm{b}}$ & nd & nd & nd \\
\hline$p$-Coumaric acid & $171.21 \pm 0.06^{\mathrm{a}}$ & $20.83 \pm 0.10^{\mathrm{c}}$ & $75.94 \pm 0.36^{\mathrm{b}}$ & $155.03 \pm 1.22^{\mathrm{a}}$ & nd & $20.17 \pm 0.08^{b}$ \\
\hline Protocatechuic acid & nd & nd & nd & $184.39 \pm 4.04^{\mathrm{a}}$ & $31.93 \pm 0.24^{\mathrm{b}}$ & $33.25 \pm 0.49^{b}$ \\
\hline Cinnamic acid & $73.42 \pm 0.17^{\mathrm{a}}$ & $53.15 \pm 0.70^{\mathrm{c}}$ & $71.69 \pm 0.15^{\mathrm{b}}$ & $69.17 \pm 0.06^{\mathrm{a}}$ & $10.81 \pm 0.01^{\mathrm{b}}$ & $11.29 \pm 0.01^{\mathrm{b}}$ \\
\hline Total & $404.37 \pm 1.28^{\mathrm{a}}$ & $97.46 \pm 1.75^{\mathrm{c}}$ & $271.47 \pm 5.76^{\mathrm{b}}$ & $464.21 \pm 6.74^{\mathrm{a}}$ & $55.08 \pm 0.08^{\mathrm{c}}$ & $89.33 \pm 1.17^{\mathrm{b}}$ \\
\hline
\end{tabular}

dw- dry weight. In each row and for each mushroom species, different letters mean significant differences $(p<0.05)$. 
Table 6. Antimicrobial activity (MIC, followed by MBC or MFC, $\mu \mathrm{g} / \mathrm{mL}$ ) of individual phenolic acids found in Volvopluteus gloiocephala and Clitocybe subconnexa, before and after in vitro digestion.

\begin{tabular}{|c|c|c|c|c|c|c|c|c|c|c|c|c|}
\hline \multirow[b]{2}{*}{ Bacteria } & \multicolumn{5}{|c|}{ Before in vitro digestion } & \multicolumn{5}{|c|}{ After in vitro digestion } & \multicolumn{2}{|c|}{ Standards } \\
\hline & HA* & CA* & CoA** & GA & $\mathbf{P A}$ & DHA & DCA & DCoA & DGA & DPA & Ampicillin & Streptomycir \\
\hline Staphylococcus & 3 & 2 & 90 & 90 & 100 & 150 & 150 & 170 & 190 & 150 & 240 & 40 \\
\hline aureus & 7 & 3 & 180 & 190 & 210 & 290 & 290 & 333 & 380 & 290 & 400 & 80 \\
\hline Bacillus & 3 & 2 & 50 & 50 & 60 & 150 & 150 & 170 & 190 & 100 & 240 & 80 \\
\hline cereus & 7 & 3 & 90 & 100 & 130 & 290 & 290 & 333 & 380 & 210 & 400 & 160 \\
\hline Micrococcus & 15 & 12 & 140 & 111 & 140 & 150 & 170 & 170 & 190 & 150 & 240 & 160 \\
\hline flavus & 30 & 30 & 180 & 230 & 210 & 290 & 330 & 333 & 380 & 290 & 400 & 320 \\
\hline Listeria & 30 & 7 & 50 & 150 & 100 & 150 & 150 & 150 & 190 & 150 & 400 & 160 \\
\hline monocytogenes & 60 & 60 & 180 & 290 & 210 & 290 & 290 & 290 & 380 & 290 & 480 & 320 \\
\hline Pseudomonas & 3 & 0.7 & 50 & 70 & 60 & 100 & 100 & 80 & 100 & 100 & 800 & 160 \\
\hline aeruginosa & 7 & 2 & 180 & 150 & 130 & 210 & 210 & 170 & 210 & 210 & 1280 & 320 \\
\hline Salmonella & 3 & 2 & 90 & 50 & 60 & 100 & 100 & 100 & 190 & 100 & 400 & 160 \\
\hline typhimurium & 7 & 3 & 180 & 100 & 130 & 210 & 210 & 210 & 380 & 210 & 480 & 320 \\
\hline Escherichia & 3 & 7 & 90 & 90 & 140 & 150 & 170 & 130 & 190 & 100 & 240 & 160 \\
\hline coli & 60 & 60 & 180 & 190 & 210 & 290 & 333 & 250 & 380 & 210 & 480 & 320 \\
\hline Enterobacter & 6 & 2 & 90 & 190 & 100 & 150 & 100 & 100 & 190 & 100 & 400 & 400 \\
\hline cloacae & 7 & 3 & 180 & 250 & 210 & 290 & 210 & 210 & 380 & 210 & 800 & 800 \\
\hline$\overline{\text { Fungi }}$ & HA* & $\mathrm{CA}^{*}$ & CoA $* *$ & GA & $\mathbf{P A}$ & DHA & DCA & DCoA & DGA & DPA & Bifonazole & $\overline{\text { Ketoconazole }}$ \\
\hline Aspergillus & 120 & 7 & 130 & 70 & 70 & 60 & 60 & 60 & 60 & 60 & 150 & 200 \\
\hline fumigatus & 250 & 20 & 250 & 150 & 150 & 130 & 130 & 130 & 130 & 130 & 200 & 500 \\
\hline Aspergillus & 20 & 7 & 130 & 60 & 60 & 50 & 50 & 50 & 50 & 50 & 150 & 150 \\
\hline ochraceus & 70 & 30 & 250 & 111 & 111 & 111 & 111 & 100 & 111 & 111 & 200 & 200 \\
\hline Aspergillus & 3 & 7 & 60 & 60 & 60 & 60 & 60 & 60 & 70 & 70 & 100 & 200 \\
\hline versicolor & 30 & 60 & 130 & 130 & 130 & 130 & 130 & 130 & 150 & 150 & 200 & 500 \\
\hline Aspergillus & 30 & 30 & 250 & 70 & 70 & 70 & 80 & 70 & 70 & 80 & 150 & 200 \\
\hline niger & 70 & 60 & 450 & 150 & 150 & 150 & 140 & 150 & 150 & 150 & 200 & 500 \\
\hline Trichoderma & 7 & 20 & 130 & 60 & 60 & 50 & 50 & 50 & 50 & 50 & 150 & 1000 \\
\hline viride & 20 & 30 & 250 & 111 & 111 & 111 & 111 & 111 & 111 & 111 & 200 & 1500 \\
\hline Penicillium & 30 & 20 & 250 & 60 & 60 & 60 & 60 & 60 & 60 & 60 & 200 & 200 \\
\hline funiculosum & 70 & 60 & 450 & 130 & 111 & 130 & 111 & 130 & 111 & 111 & 250 & 500 \\
\hline Penicillium & 60 & 30 & 130 & 60 & 60 & 60 & 60 & 60 & 60 & 60 & 200 & 1000 \\
\hline ochrochloron & 70 & 60 & 250 & 130 & 130 & 130 & 111 & 130 & 130 & 130 & 250 & 1500 \\
\hline Penicillium & 60 & 7 & 130 & 60 & 60 & 60 & 60 & 60 & 60 & 60 & 200 & 1500 \\
\hline verrucosum & 070 & 30 & 250 & 130 & 130 & 130 & 130 & 111 & 111 & 130 & 300 & 2000 \\
\hline
\end{tabular}


MIC- minimal inhibitory concentrations; MBC- bactericidal concentrations; MFC- fungicidal concentrations; HA- $p$-Hydroxybenzoic acid; CA- Cinnamic acid; CoA- $p$ Coumaric acid; PA- Protocatechuic acid; DHA- In vitro digested $p$-hydroxybenzoic acid; DCA- In vitro digested cinnamic acid; DCoA- In vitro digested $p$-coumaric acid; GA- Gallic acid; DGA- In vitro digested gallic acid; DPA- In vitro digested protocatechuic acid. * Previously published in Heleno et al. 2013 . ** Previously published in Heleno et al., 2014. 

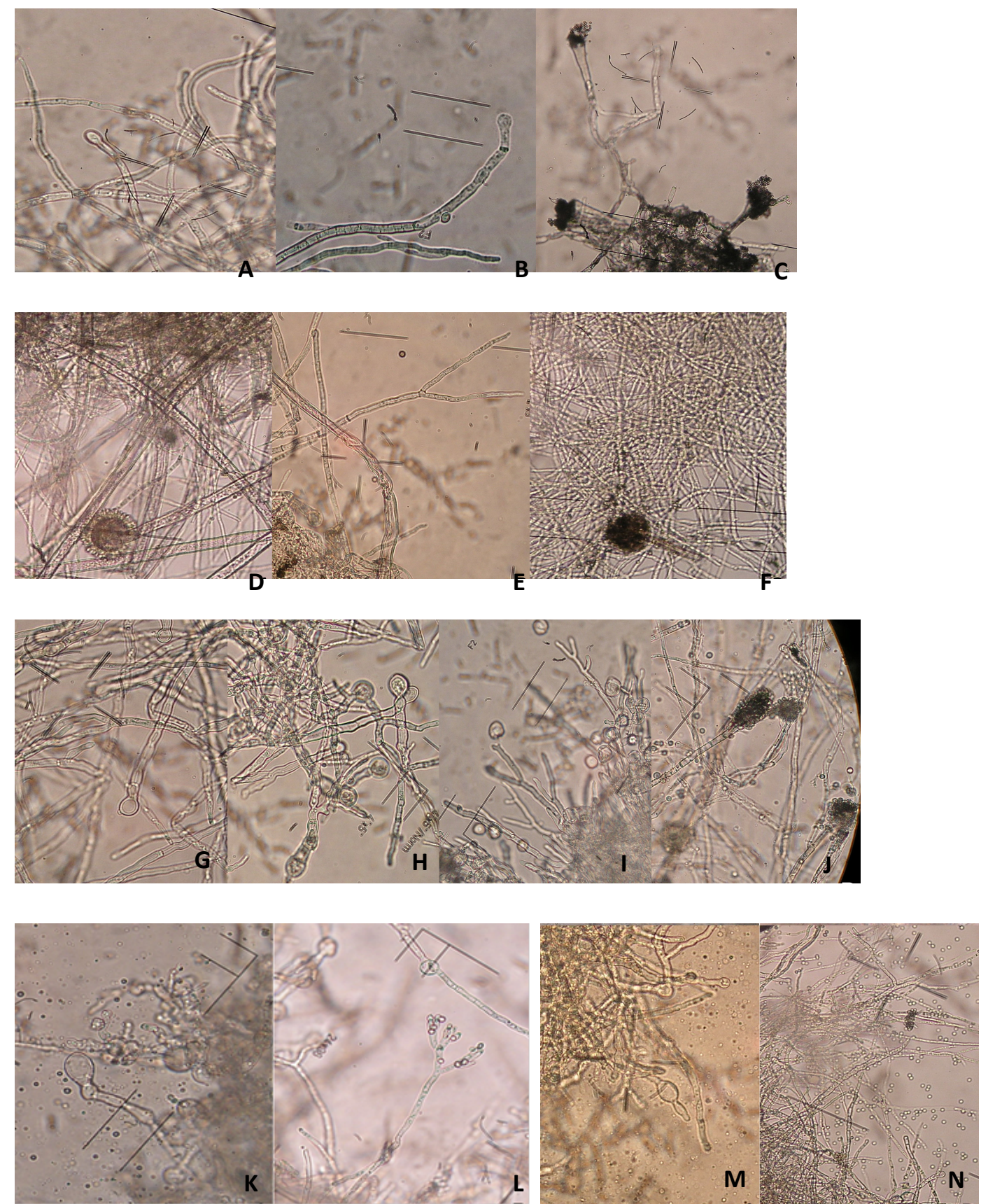

Figure 1. Demelanizing activity of gallic acid against different fungi at different concentrations: A- $31.25 \mu \mathrm{g} / \mathrm{mL}$ on A. fumigatus, B- $62.5 \mu \mathrm{g} / \mathrm{mL}$ on A. fumigatus, Ccontrol A. fumigatus, D- $62.5 \mu \mathrm{g} / \mathrm{mL}$ on $A$. niger, E- $125 \mu \mathrm{g} / \mathrm{mL}$ on $A$. niger, F- control A. niger, G- $15.6 \mu \mathrm{g} / \mathrm{mL}$ on $P$. funiculosum, $\mathbf{H}-31.25 \mu \mathrm{g} / \mathrm{mL}$ on $P$. funiculosum, I- 62.5 $\mu \mathrm{g} / \mathrm{mL}$ on $P$. funiculosum, $\mathbf{J}$ - control $P$. funiculosum, $\mathbf{K}-31.25 \mu \mathrm{g} / \mathrm{mL}$ on $P$. 
ochrochloron, L- control P. ochrochloron, M- $31.25 \mu \mathrm{g} / \mathrm{mL}$ on $P$. veruccosum var. cyclopium, $\mathbf{N}$ - control $P$. veruccosum var. cyclopium. 